\title{
REDES DE COOPERAÇÃO E INOVAÇÃO LOCALIZADA: ESTUDO DE CASO DE UM ARRANJO PRODUTIVO LOCAL
}

\author{
Carlos Olavo Quandt \\ Doutorado em Administração da Pontifícia Universidade Católica do Paraná - PUCPR \\ Professor da Pontifícia Universidade Católica do Paraná - PUCPR \\ E-mail: carlos.quandt@pucpr.br (Brasil)
}

\section{RESUMO}

As estratégias coletivas de cooperação entre organizações e pessoas constituem uma das principais formas de participação efetiva dos atores sociais na geração de inovações e, consequentemente, na competitividade e crescimento econômico de empresas, regiões e países. A crescente importância dos aglomerados de inovação e das alianças e redes interorganizacionais reforça a relevância da temática do presente estudo, que visa ampliar a compreensão do processo de formação de redes locais e sua contribuição para a geração de inovações. A abordagem adotada privilegia as interações e o intercâmbio de informações e conhecimento entre os atores públicos e privados que estão inseridos nas redes locais. O contexto empírico da análise é um estudo de caso do arranjo produtivo local (APL) de malharias de Imbituva, no Estado do Paraná. Os resultados revelaram que as inovações no APL em geral foram pouco expressivas, e que o seu impacto nas organizações foi bastante limitado. Verificouse uma relação positiva entre intensidade de interações, propensão a inovar e desempenho dos negócios. Observou-se também que as empresas mais antigas apresentam um padrão mais intenso de interações. A análise de redes evidencia que os aspectos relacionados à inovação e às interações locais ainda se encontram pouco desenvolvidos, sugerindo a importância de iniciativas que estimulem a inovatividade e a intensificação do aprendizado pela interação com outras empresas e instituições do APL.

Palavras-Chave: Arranjo Produtivo Local; Redes; Cooperação; Desenvolvimento; Inovação. 


\section{INTRODUÇÃO}

O desenvolvimento econômico e a competitividade de firmas e nações dependem cada vez mais do papel estratégico do conhecimento e da inovação. A capacidade de criar novos conhecimentos constitui uma importante vantagem competitiva, e depende em grande parte da exploração da diversidade de competências complementares que podem ser utilizadas, dentro e fora da organização (Quandt, 2009). Em outras palavras, a inovação é um processo multidimensional, associado à convergência de conhecimentos complementares, processos de interação e mecanismos de apoio à cooperação em contextos específicos.

As iniciativas e políticas para monitorar e estimular a geração de inovações tendem a privilegiar os aspectos técnicos do processo e os indicadores de investimentos tecnológicos nas empresas (Freeman, 1995). Observa-se que uma análise centrada nos indicadores de desempenho (outputs ou resultados do processo de inovação como um todo) é útil para a identificação de necessidades e potencialidades. Porém, ela não esclarece os motivos da existência de lacunas com relação aos parâmetros desejáveis, nem propicia um plano de ação para resolvê-los. A análise de inputs da inovação apresenta limitações ainda maiores, pois estes não estão necessariamente associados a resultados concretos (Crossan \& Apaydin, 2010).

Assim, evidencia-se a necessidade de uma abordagem da capacidade de inovação (ou inovatividade) como forma de preencher esta necessidade estratégica, tanto do ponto de vista empresarial como da perspectiva regional e nacional de estímulo ao desenvolvimento, por meio da investigação das diversas dimensões da inovação em diferentes contextos. A abordagem não deve se restringir à avaliação do processo de desenvolvimento tecnológico e sua exploração nas empresas, mas analisar a inovatividade como um conjunto integrado e dinâmico de elementos da organização e dos atores com os quais ela se relaciona, que interagem para criar e reforçar um ambiente de estimulo à inovação (Crossan \& Apaydin, 2010; Lynch, Walsh, \& Harrington, 2010).

Esta visão reflete as mudanças que as organizações estão realizando no seu formato de gestão e nas suas relações com outros agentes econômicos. O isolamento e as estruturas hierárquicas verticalizadas tendem a dar lugar a arranjos organizacionais que privilegiam a comunicação horizontal, a combinação multifuncional de competências, a aprendizagem e a absorção de conhecimento por meio da construção de redes. Numa rede, a informação não obedece a hierarquias, mas é transmitida de maneira horizontal, recíproca e interativa. Consequentemente, a eficácia do sistema depende da capacidade de integrar tipos diferentes de informação codificada e conhecimento tácito, e difundi-los por meio de interações entre os diferentes agentes e tipos de atividades. A necessidade de um enfoque abrangente evidencia-se também pela importância crescente dos aglomerados de inovação - 
caracterizados como clusters ou arranjos produtivos locais (APLs). Este tipo de arranjo facilita a aprendizagem coletiva e a inovação através de coordenação implícita e explícita (Altenburg \& MeyerStamer, 1999; Baptista \& Swann, 1998; Cassiolato \& Szapiro, 2003).

Portanto, uma abordagem integrada dos vínculos que se estabelecem em aglomerados e redes é fundamental para a compreensão do processo de inovação, enfatizando três dimensões: 1) aspectos de gestão da empresa, principalmente quanto à sua estratégia, competências técnicas, orientação para o mercado e inovatividade; 2) identificação das diferentes configurações dos sistemas interorganizacionais que se constituem em aglomerados produtivos; e 3) análise de padrões de interação em redes interorganizacionais e seu papel na difusão do conhecimento tecnológico, aprendizagem e inovatividade.

O presente artigo pretende contribuir para a melhor compreensão do processo de formação de redes locais e sua contribuição para a geração de inovações, com um enfoque que privilegia as interações e o intercâmbio de informações e conhecimento. $\mathrm{O}$ objetivo principal do estudo é investigar como as interações dos diversos agentes que atuam em APLs contribuem para o desenvolvimento da sua inovatividade e, consequentemente, inovações em produtos e processos, e para o aumento da competitividade e desenvolvimento econômico local. Em contraste com as abordagens tradicionais de análise locacional, o foco principal da investigação não está nas características territoriais dos aglomerados de inovação ou nos atributos de seus atores isolados, mas nos vínculos entre os atores públicos e privados que estão inseridos nas redes locais. A partir desse arcabouço conceitual, desenvolveu-se o estudo de caso do APL de malharias de Imbituva, no Estado do Paraná.

\section{FUNDAMENTAÇÃO TEÓRICA DA PESQUISA}

\subsection{INOVAÇÃO}

O conceito de inovação é distinto da criatividade, das ideias e invenções. Uma invenção é a concepção de algo inédito, independentemente de sua utilidade prática ou aplicação comercial. A inovação refere-se à transformação efetiva do conhecimento em valor, a partir da introdução no mercado de novos produtos, processos ou sistemas. Portanto, uma invenção só se torna uma inovação ao realizar seu potencial econômico. Enquanto a invenção é essencialmente técnica, o processo de inovação compreende diversas atividades científicas, tecnológicas, organizacionais, financeiras, comerciais e mercadológicas.

Inovação tecnológica é a implementação de produtos (bens ou serviços) ou processos tecnologicamente novos ou substancialmente aprimorados, conforme o Manual de Oslo (Organisation 
for Economic Co-Operation and Development [OCDE], 1997). A inovação ocorre quando o produto é introduzido no mercado ou quando o processo passa a ser operado pela empresa. Inovação gerencial e organizacional compreende a introdução de novas estruturas organizacionais, a implementação de técnicas avançadas de gestão ou uma orientação estratégica corporativa nova ou substancialmente modificada. Em resumo, inovação refere-se à geração de valor a partir de invenções, conhecimentos técnicos, práticas organizacionais e processos de produção.

O grau de inovação geralmente é expresso pela distinção entre inovações incrementais, que apenas aperfeiçoam produtos, processos e serviços existentes, e inovações radicais, que se referem a produtos, processos ou formas de organização inteiramente novos. O grau de inovação pode ser avaliado também com referência à sua novidade em um determinado contexto. O produto ou processo pode ser novo para a empresa, não sendo necessariamente novo para o mercado, setor de atuação, para o país ou para o mundo. Segundo a OCDE (1997), os produtos e processos que representam uma inovação para a empresa, mesmo que já tenham sido implementados por outros, são relevantes para a avaliação da atividade inovativa.

As inovações podem propiciar reduções de custos, ganhos na produtividade e qualidade, e o potencial de lucros extraordinários aos empreendedores. Por outro lado, a introdução de inovações é uma atividade repleta de incertezas, resultantes da evolução da tecnologia, das mudanças constantes do mercado, da dificuldade de prever as ações dos concorrentes, da escassez de recursos para o desenvolvimento tecnológico e outros fatores. O risco total é elevado, porque cada um dos fatores apresenta desafios independentes: por exemplo, um sucesso tecnológico não implica um eventual sucesso comercial.

O desenvolvimento contínuo da inovatividade da empresa exige uma atitude de aprendizagem e uma visão da inovação como um processo estratégico, integrado ao seu conjunto de práticas de gestão, e não como um esforço isolado. A grande maioria das empresas considera a inovação como um fator estratégico para manter a sua competitividade. Cada vez mais, a inovação também faz parte da estratégia de negócios das pequenas e médias empresas, que hoje enfrentam concorrentes externos em mercados que eram exclusivamente locais, mas vislumbram oportunidades de expandir sua área de atuação. Contudo, poucas empresas no Brasil incorporam a inovação de maneira explícita e sistemática na sua formulação estratégica. Um número ainda menor de empresas adota práticas efetivas de gestão do processo de inovação. Em geral, as empresas brasileiras investem pouco em pesquisa e desenvolvimento, inovam pouco, registram poucas patentes e não tiram partido das oportunidades de fomento à inovação, transferência de tecnologia e cooperação com universidades, institutos de pesquisa e outras empresas (Federação das Indústrias do Estado de São Paulo [FIESP], 2005; Instituto Brasileiro de Geografia e Estatística [IBGE], 2003).

Revista de Administração e Inovação, São Paulo, v. 9, n. 1, p.141-166, jan./mar. 2012. 


\subsection{REDES INTERORGANIZACIONAIS}

No campo da administração, o interesse crescente na formação de alianças e redes está associado à percepção da necessidade de ampliar e diversificar os recursos e competências necessários à manutenção da competitividade de uma dada organização (Borgatti \& Foster, 2003), notadamente com vistas à exploração de capacitações complementares. De acordo com Olivares (2002), a literatura sobre mudança organizacional vem dedicando atenção especial à área de desenho organizacional, diante das mudanças no ambiente de negócios e das adaptações necessárias na configuração das relações internas e externas das organizações.

A perspectiva de redes abriu novos rumos para as pesquisas que visam entender as diferenças de conduta estratégica e desempenho que existem entre as empresas. A abordagem tradicional enfoca a empresa como entidade autônoma e isolada, cujas vantagens competitivas estão associadas a características do setor (Porter, 1980), ou a recursos e competências internas (Barney, 1991). As abordagens contemporâneas reconhecem a crescente importância de redes estratégicas com formatos e alcances variados, que vinculam a empresa horizontalmente e verticalmente a outras organizações, como fornecedores, clientes, parceiros, concorrentes e outros tipos de entidades. Assim, a rede amplia o conceito de estrutura organizacional para além da empresa, e eventualmente além do seu território e setor. Enquanto o conceito da estrutura tradicional abrange uma única organização, na rede o contexto se amplia para as relações simultâneas e interdependentes entre organizações de naturezas distintas. Com isso, ampliam-se os desafios gerenciais relacionados à criação, implementação e manutenção da arquitetura organizacional (Cândido \& Abreu, 2000).

Os novos tipos de arranjos empresariais exigem formas de governança capazes de conciliar competição e cooperação, autonomia e interdependência para o desenvolvimento sinérgico das competências dos membros da rede. As evidências indicam que as empresas que não estão engajadas em cooperação e trocas de conhecimento formal e informal limitam sua base de conhecimento no longo prazo e reduzem sua capacidade de participar em relações de intercâmbio (Pittaway, Robertson, Munir, \& Denyer, 2004). Numa rede, o processo de inovação emerge do compartilhamento de conhecimentos diversificados, da reflexão sobre experiências, e do aprendizado pela interação e experimentação (Berry, 1997). Os estudos de Bengtsson e Sölvell (2004), Love e Roper (1999) e MacPherson (1997), por exemplo, mostram que a intensidade de interação em rede está positivamente correlacionada à geração de inovações. Aral e Van Alstyne (2008) demonstraram a relação entre a formação de redes, o acesso a informações novas e o desempenho empresarial. Um amplo estudo de Porter e Ketels (2003) sobre a competitividade de empresas britânicas verificou que o estabelecimento de redes interorganizacionais é um fator crítico para o desenvolvimento da inovatividade.

Revista de Administração e Inovação, São Paulo, v. 9, n. 1, p.141-166, jan./mar. 2012. 
Em resumo, a constituição de redes de inovação passou a ser vista como um importante fator na configuração da estratégia competitiva. Evidencia-se também que a análise e o desenho de intervenções para esse tipo de rede interorganizacional requerem uma metodologia caracterizada pelo foco nas interações, no diálogo e na difusão do conhecimento entre os agentes, ao contrário do foco convencional nas características isoladas dos agentes e nas dotações locacionais das regiões onde atuam. Em redes territoriais, o aprendizado coletivo e cumulativo é essencial para gerar respostas inovadoras aos novos desafios e assegurar o desenvolvimento sustentado do cluster num ambiente caracterizado pela incerteza e mudança constante (Camagni, 1995).

A competitividade da empresa está relacionada à sua localização, uma vez que os vínculos espaciais que se estabelecem entre empresas, clientes e outras instituições afetam a vantagem competitiva. O fenômeno de concentração geográfica de empresas de um mesmo setor é estudado há muito tempo, desde o trabalho pioneiro de Marshall no início do século XX. O tema recebeu atenção renovada a partir dos estudos de Porter (1993, p. 209), que define aglomerados ou clusters como "concentrações geográficas de empresas inter-relacionadas, fornecedores especializados, prestadores de serviços, empresas em setores correlatos e outras instituições específicas (universidades, órgãos de normatização e associações), que competem mas também cooperam entre si”. São organizações vinculadas por elementos comuns e complementares. Este escopo geográfico variável abrange bairros, cidades, estados ou até países vizinhos. Porter (1993) destaca que os aglomerados são sistemas de empresas e instituições inter-relacionadas, em que o todo é maior do que a soma das partes, desempenhando um papel importante na competição e trazendo implicações relevantes para as empresas, governos, universidades e outras instituições.

\section{METODOLOGIA}

A abordagem metodológica do presente estudo caracteriza-se como exploratória descritiva, com a adoção de técnicas qualitativas e quantitativas. A metodologia de análise de redes sociais foi aplicada a partir da elaboração de matrizes, que possibilitam a percepção dos elos existentes entre os atores nos contextos gerais e específicos para cada tipo de interação. Os elos enviados e recebidos pelos atores permitem a elaboração de sociogramas, bem como cálculos de parâmetros como graus de densidade, centralidade local e global, e a identificação de subgrupos na rede (Wasserman \& Faust, 1999).

A investigação das interações entre os atores públicos e privados que estão inseridos na estrutura de redes do APL de malhas de Imbituva busca esclarecer as seguintes questões:

- Como se caracterizam as empresas do APL, e quais são os elementos-chave do seu processo de desenvolvimento?

Revista de Administração e Inovação, São Paulo, v. 9, n. 1, p.141-166, jan./mar. 2012. 
- Quais são as atividades e tipos de inovações no APL?

- O que os parâmetros da análise de redes revelam sobre os padrões de interação e o papel relativo dos diversos agentes envolvidos no APL?

- O que os parâmetros da análise de redes revelam sobre o estágio de desenvolvimento da rede local?

- Quais são os principais tipos de interações e formas de intercâmbio de informações e conhecimento que ocorrem nas redes locais?

- Qual é a contribuição efetiva das diversas modalidades de intercâmbio e seu conteúdo para o fomento à inovação no contexto das redes locais?

- Quais são as barreiras e facilitadores ao compartilhamento do conhecimento, e ao consequente desenvolvimento das empresas no APL?

A partir dos resultados das questões acima, procurou-se evidenciar quais atividades são mais efetivas para a construção e sustentação dos estágios sucessivos do desenvolvimento de aglomerados de inovação.

\section{APRESENTAÇÃO E ANÁLISE DOS DADOS DA PESQUISA}

\subsection{O APL DE MALHARIAS DE IMBITUVA}

O município de Imbituva está localizado na região Sudeste do Estado do Paraná, a $180 \mathrm{~km}$ da capital do Estado e a 76 km de Ponta Grossa. A população total de Imbituva em 2005 era de 28.320 habitantes. Na década de 1990, o município registrou aumento de 9,72\% para a população urbana e redução de 2,22\% para a rural. A taxa de crescimento total no período foi de 3,30\%, superior ao dobro do Estado, cujo valor foi de 1,4\% ao ano (Instituto Paranaense de Desenvolvimento Econômico e Social [Ipardes], 2006).

Imbituva apresenta Índice de Desenvolvimento Humano (IDH-M) de 0,727, inferior à média estadual e brasileira, que são de 0,787 e 0,764 respectivamente. A agropecuária responde por $36 \%$ do Produto Interno Bruto (PIB) municipal, a indústria por $13 \%$ e o setor de serviços por $51 \%$. A principal atividade industrial é a madeira, além de cerâmica, vestuário, tecidos, calçados, produtos minerais não metálicos e borracha (Hoffman \& Lins, 2002).

Um levantamento realizado pelo Ipardes em 2005 verificou que Imbituva abriga o maior número de empresas produtoras de malhas retilíneas e tricô do Estado, indicando a importância dessa atividade para a economia local, em termos de geração de emprego e renda. O APL de malhas de Imbituva é 
composto somente por micro e pequenas empresas. Além do trabalho formal, o polo das malhas gera um número considerável de empregos informais, caracterizados pela terceirização de serviços como bordados, crochê e acabamentos. Porém, o ramo madeireiro é a atividade industrial mais importante no município, no que se refere à geração de empregos industriais formais, com 50\% do total de empregos industriais de Imbituva. Observa-se também que as atividades ligadas à madeira ocupam predominantemente mão de obra masculina, enquanto o ramo de malharias é o principal responsável pelo emprego feminino, e o segundo maior segmento industrial.

A primeira malharia instalou-se no município por volta de 1975. Posteriormente, diversos moradores abriram suas próprias malharias no local, ou passaram a prestar serviços às empresas estabelecidas, a partir do processo gradativo de aprendizagem e da percepção do potencial do negócio, em boa parte dos casos como forma de complementação de renda. No início da década de 1980, por iniciativa de uma nova moradora do local, iniciou-se o processo de trabalho conjunto e institucionalização do polo de malhas, com o envolvimento dos empresários e da Prefeitura. Em 1983, foi criada a Imbitumalhas - Associação das Malharias de Imbituva, e realizou-se a primeira Feira de Malhas de Imbituva, que propiciou maior visibilidade aos produtores locais e estimulou o crescimento

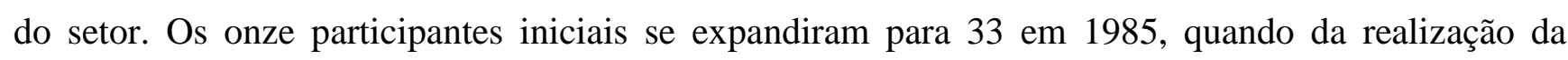
terceira feira, passando para 70 na quarta feira, e mais de 100 em 1990 (Hoffman \& Lins, 2002).

Contudo, o polo de Imbituva sofreu uma contração com a crise que atingiu os setores têxtil e de vestuário no Brasil a partir do início da década de 1990, como resultado das mudanças macroeconômicas e a abertura do mercado interno à concorrência dos importados (Gorini, 2000). Muitas empresas fecharam suas portas, e iniciou-se um processo de reestruturação produtiva na região. Com a aquisição crescente de máquinas mais modernas e de melhor nível tecnológico, foi possível manter ou aumentar a capacidade de produção local, mesmo com a diminuição do número de empresas e de empregos. Alguns desses maquinários, em especial as máquinas italianas de tecelagem computadorizada, facilitam a produção de peças semiacabadas na mesma máquina. Os estabelecimentos que não adotaram os avanços tecnológicos sofrem sérias desvantagens em produtividade e competitividade. Outro fator que vem afetando as empresas de malhas no local, segundo depoimentos dos empresários, são as modificações climáticas no Paraná, que ocasionaram uma amenização nas temperaturas do inverno nos últimos anos, notadamente a partir de 2004.

Como grande parte da produção local se destina às estações frias, os produtos são confeccionados durante o ano todo para serem comercializados neste período. As empresas do APL comercializam seus produtos nas próprias fábricas e lojas, e, com grande intensidade, na Feira de Malhas, evento que acontece anualmente no outono. A produção é comercializada principalmente para 
os municípios do Paraná, mas também se destina aos estados de São Paulo, Santa Catarina e Rio Grande do Sul.

O estudo de caso do APL de malhas de Imbituva foi realizado em duas etapas. Na primeira, fezse um levantamento bibliográfico sobre APLs no Brasil e no Paraná, bem como de textos específicos e dados secundários sobre o caso em estudo. Na segunda etapa da pesquisa, foram investigadas todas as empresas e as principais instituições (locais e externas) que atuam no APL de malhas de Imbituva. A pesquisa de campo foi realizada nos meses de abril e maio de 2007, utilizando-se como instrumento de pesquisa a entrevista estruturada. O trabalho de campo contou com o apoio da Associação das Malharias de Imbituva (Imbitumalhas), que auxiliou nos contatos com as 43 malharias que fazem parte do cadastro de empresas associadas.

\subsection{PERFIL DAS EMPRESAS DO APL DE IMBITUVA}

As empresas pesquisadas englobam um período de fundação que vai da primeira empresa, em 1975, até a mais recente, em 2006. A idade média das empresas é de 11,4 anos, indicando que uma boa parte delas enfrentou o período de crise e reestruturação que afetou o setor. Cerca de $40 \%$ das malharias existem há mais de 10 anos. Por outro lado, o fato de 14\% delas (6 empresas de um total de 43) terem sido criadas há menos de 5 anos reflete a consolidação e renovação do polo. Na maior parte, as empresas foram iniciadas para complementar a renda familiar ou proporcionar sustento básico, com perspectivas modestas de crescimento para mercados mais amplos. Os dois primeiros motivos foram indicados por cerca de $58 \%$ das empresas, conforme indica a Tabela 1.

Tabela 1 - Motivo principal para iniciar a empresa.

\begin{tabular}{l|c}
\multicolumn{1}{c|}{ Motivo } & Proporção de empresas \\
\hline Sustento familiar básico & $18,6 \%$ \\
\hline Complemento de renda & $39,5 \%$ \\
\hline Perspectiva de crescimento local e regional & $34,9 \%$ \\
\hline Perspectiva de crescimento nacional e internacional & $0,0 \%$ \\
\hline Outro & $7,0 \%$ \\
\hline
\end{tabular}

Fonte: Elaborado pelo autor.

As malharias se caracterizam por gestão empresarial familiar, com o envolvimento de pessoas com vínculos de parentesco nas atividades da empresa. Há uma predominância de pequenos empreendimentos, pois $40 \%$ das malharias empregam 5 pessoas ou menos. A média geral é de 8,4 funcionários por empresa, incluindo os proprietários. Um aspecto marcante é a predominância de mulheres, tanto na composição geral da força de trabalho quanto no comando das empresas. Quase todas as malharias (98\%) possuem pelo menos uma mulher entre os sócios e/ou pessoas da família 
envolvidas ativamente nos negócios. Por outro lado, mais da metade, ou 51,2\% das empresas, não possui um homem sequer entre os proprietários e sócios que atuam na empresa.

Quanto aos funcionários contratados, formais e informais, cerca de $90 \%$ das empresas utilizam mão de obra exclusivamente feminina. Considerando todo o pessoal ocupado - proprietários, familiares, funcionários e terceiros que prestam serviços regulares à empresa -, a proporção é de quase oito mulheres para cada homem envolvido nas atividades das malharias (Tabela 2). No total, 360 pessoas trabalham nas empresas do APL, sendo 44 homens e 316 mulheres.

Tabela 2 - Pessoal ocupado nas malharias de Imbituva.

\begin{tabular}{l|c|c|c}
\multicolumn{1}{c|}{ Tipo } & Homens & Mulheres & Total \\
\hline Proprietários/Familiares & 29 & 73 & 102 \\
\hline Funcionários Formais & 12 & 126 & 136 \\
\hline Funcionários Informais & 0 & 18 & 18 \\
\hline Terceirizados regulares & 3 & 99 & 102 \\
\hline
\end{tabular}

Fonte: Elaborado pelo autor.

Entre os produtos das malharias, predominam os artigos femininos para o inverno, que estão entre os produtos principais de mais de $80 \%$ das empresas. Além disso, $63 \%$ das malharias produzem artigos masculinos, e apenas $37 \%$ fabricam artigos infantis. Aproximadamente um terço das empresas locais produz malhas mais leves, para o verão. Os dados gerais sobre tipos de produtos estão apresentados na Tabela 3. Os totais por tipo superam 100\% porque uma mesma empresa pode fabricar diversos tipos de produtos.

Tabela 3 - Tipos de Produtos.

\begin{tabular}{l|c}
\multicolumn{1}{c|}{ Produtos Principais } & Proporção de Empresas \\
\hline Artigos para Inverno & $81,4 \%$ \\
\hline Artigos para Verão & $32,6 \%$ \\
\hline Moda Feminina & $79,1 \%$ \\
\hline Moda Masculina & $62,8 \%$ \\
\hline Moda Infantil & $37,2 \%$ \\
\hline
\end{tabular}

Fonte: Elaborado pelo autor.

\subsection{EVOLUÇÃO DAS EMPRESAS}

O roteiro de pesquisa incluiu uma investigação sobre a evolução dos negócios nos quatro anos anteriores à pesquisa de campo. Em face da dificuldade de obter dados numéricos para quantificar com precisão as mudanças no período, optou-se por enfocar a percepção dos empresários quanto à evolução da sua empresa. Analisando os dados gerais para esse período, observa-se uma clara tendência à redução do emprego nas malharias de Imbituva nos quatro anos anteriores à pesquisa (Tabela 4). Para mais da metade das empresas, houve uma redução no número de funcionários, enquanto houve 
aumento em menos de $10 \%$ delas. O faturamento teve um comportamento similar no mesmo período. Mais de $60 \%$ das empresas relataram uma redução nas vendas, em contraste com cerca de $19 \%$ que informaram um aumento.

Tabela 4 - Evolução das empresas no período 2003-2006.

\begin{tabular}{l|c|c|c|c}
\hline & $\begin{array}{c}\text { Número de } \\
\text { funcionários }\end{array}$ & $\begin{array}{c}\text { Produção (no } \\
\text { de peças) }\end{array}$ & Faturamento & $\begin{array}{c}\text { Estrutura } \\
\text { (instalações } \\
\text { físicas/maquinário) }\end{array}$ \\
\hline Aumentou muito & $2,3 \%$ & $9,3 \%$ & $7,0 \%$ & $16,3 \%$ \\
\hline Aumentou pouco & $7,0 \%$ & $16,3 \%$ & $11,6 \%$ & $14,0 \%$ \\
\hline Permaneceu estável & $30,2 \%$ & $30,2 \%$ & $14,0 \%$ & $60,5 \%$ \\
\hline Diminuiu um pouco & $14,0 \%$ & $18,6 \%$ & $23,3 \%$ & $2,3 \%$ \\
\hline
\end{tabular}

Fonte: Elaborado pelo autor.

Com relação à produção, a queda foi menos pronunciada, ocorrendo em 37\% das empresas. Por outro lado, mais de $25 \%$ das empresas indicaram que houve expansão da produção nesse período. A proporção de empresas que ampliaram sua estrutura de produção é significativa (mais de 30\%), enquanto poucas apresentaram redução. $\mathrm{O}$ item relativo à estrutura apresenta o maior número de respostas por parte das empresas que relataram condições estáveis nesses quatro anos, com $60 \%$ das respostas. Cerca de 30\% das empresas também indicam estabilidade no número de funcionários e na produção.

De fato, quando perguntadas sobre a etapa que descreve melhor a situação atual da empresa, 21 empresários $(48,8 \%)$ a qualificaram como estabilidade (Tabela 5). Em contraste, evidencia-se um aspecto preocupante a partir da segunda resposta mais comum, que foi propenso a encerrar ou vender a empresa, com 9 empresas, ou 20,9\% das respostas. Uma pequena proporção dos empresários indicou que a etapa atual pode ser descrita como fase inicial de operações (7\%) ou crescimento inicial com recursos próprios $(4,7 \%)$. Da mesma forma, apenas 2 empresas indicaram que estão em processo de expansão, o que corresponde a 4,7\% do total.

Tabela 5 - Situação atual das empresas.

\begin{tabular}{l|c|c}
\multicolumn{1}{c|}{ Descrição } & \multicolumn{2}{|c}{ Empresas } \\
\hline Fase inicial de operações & 3 & $7,0 \%$ \\
\hline Crescimento inicial com recursos próprios & 2 & $4,7 \%$ \\
\hline Crescimento com financiamento externo & 6 & $14,0 \%$ \\
\hline Estabilidade & 21 & $48,8 \%$ \\
\hline Em processo de expansão & 2 & $4,7 \%$ \\
\hline
\end{tabular}

Fonte: Elaborado pelo autor.

As principais fontes de recursos financeiros para a empresa durante o período 2003-2006 foram o faturamento próprio e investimentos feitos pelos próprios empresários e familiares. Os empréstimos bancários, tanto privados como públicos, foram pouco utilizados. A Tabela 6 indica a média das Revista de Administração e Inovação, São Paulo, v. 9, n. 1, p.141-166, jan./mar. 2012. 
respostas de todas as empresas, porém as proporções da utilização dessas fontes de recursos financeiros apresentam variações significativas entre elas. Por exemplo, quase metade das malharias obteve $80 \%$ ou mais dos recursos necessários do seu próprio faturamento, complementando com recursos de outras fontes. Enquanto $70 \%$ das empresas dizem não ter usado recursos públicos e $77 \%$ não utilizaram empréstimos privados, uma proporção significativa (mais de um terço das empresas) obteve financiamentos públicos ou privados para cobrir até $40 \%$ das suas necessidades de recursos no período.

Tabela 6 - Origem dos recursos no período 2003-2006.

\begin{tabular}{l|c}
\multicolumn{1}{c|}{ Fontes de recursos } & Média de todas as empresas \\
\hline Faturamento próprio (vendas) & $67 \%$ \\
\hline Investimentos próprios (pessoais), familiares ou amigos & $19 \%$ \\
\hline Financiamento público & $7 \%$ \\
\hline Financiamento privado & $7 \%$ \\
\hline Total & $100 \%$ \\
\hline
\end{tabular}

Fonte: Elaborado pelos autores.

\subsection{ABRANGÊNCIA GEOGRÁFICA DOS INSUMOS E MERCADOS}

A pesquisa procurou também investigar o alcance geográfico das empresas de Imbituva, tanto em relação às origens dos seus recursos produtivos como ao destino da produção. A Tabela 7 indica os percentuais médios referentes aos locais de origem dos recursos. Observa-se o papel limitado dos recursos locais, o que denota a falta de aprofundamento e especialização produtiva no arranjo. Os percentuais mais altos - que chegam a apenas $20 \%$ - referem-se à aquisição de máquinas e equipamentos, e de recursos financeiros, provavelmente junto às agências bancárias locais.

Observa-se também o papel significativo que é atribuído aos serviços de consultoria e treinamento de origem regional (de um modo geral, o próprio Estado do Paraná), possivelmente relacionado à atuação de entidades como o Serviço de Apoio às Micro e Pequenas Empresas (Sebrae) e Instituto Euvaldo Lodi (IEL) junto ao arranjo. Grande parte dos insumos para a produção vem de outros estados, e as relações internacionais praticamente se resumem à aquisição de máquinas importadas. 
Tabela 7 - Origem dos recursos produtivos no período 2003-2006.

\begin{tabular}{l|c|c|c|c|c}
\hline Área de origem & $\begin{array}{c}\text { Máquinas/ } \\
\text { Equipamentos }\end{array}$ & $\begin{array}{c}\text { Insumos } \\
\text { gerais }\end{array}$ & $\begin{array}{c}\text { Insumos } \\
\text { especializados }\end{array}$ & $\begin{array}{c}\text { Serviços de } \\
\text { consultoria e } \\
\text { treinamento }\end{array}$ & $\begin{array}{c}\text { Recursos } \\
\text { financeiros }\end{array}$ \\
\hline Local & $20 \%$ & $2 \%$ & $15 \%$ & $17 \%$ & $20 \%$ \\
\hline Regional & $10 \%$ & $13 \%$ & $17 \%$ & $40 \%$ & $9 \%$ \\
\hline Nacional & $34 \%$ & $82 \%$ & $31 \%$ & $8 \%$ & $19 \%$ \\
\hline Internacional & $36 \%$ & $3 \%$ & $6 \%$ & $0 \%$ & $2 \%$ \\
\hline Total & $100 \%$ & $100 \%$ & $69 \%^{*}$ & $65 \% *$ & $50 \% *$ \\
\hline
\end{tabular}

* Nota: As somas não atingem $100 \%$ porque diversas empresas afirmam não utilizar insumos especializados, serviços de consultoria e treinamento, ou recursos financeiros externos.

Fonte: Elaborado pelo autor.

Com relação ao alcance geográfico das vendas das empresas de Imbituva, fica evidente a sua limitação, conforme ilustra a Tabela 8. Em média, o próprio Estado do Paraná responde por dois terços do mercado das malharias. Uma pequena proporção (15\%) é vendida localmente, e parte desta é revendida eventualmente em outros locais; cerca de 15\% também se destina a outros estados do Sul, principalmente Santa Catarina.

Tabela 8 - Mercados de destino.

Destino da Produção (média de todas as empresas)

\begin{tabular}{l|c}
\multicolumn{1}{c|}{ Mercado } & \% do total \\
\hline Local & $15 \%$ \\
\hline Estado & $67 \%$ \\
\hline Região Sul & $15 \%$ \\
\hline Nacional & $3 \%$ \\
\hline Internacional & $0 \%$ \\
\hline Total & $100 \%$ \\
\hline
\end{tabular}

Fonte: Elaborado pelo autor.

Uma análise mais detalhada das respostas revela que mais da metade das empresas não trabalha com vendas locais, e quase a mesma proporção (47\% das empresas) não vende para outros estados. Segundo os empresários, uma parte insignificante da produção total do APL (cerca de 3\% em média) vai para outros mercados, geralmente para São Paulo. Em contraste, existem cinco empresas com presença mais agressiva em mercados nacionais, e destinam $40 \%$ ou mais da sua produção para mercados fora do Paraná. Elas representam cerca de 12\% do total de empresas do APL. Destaca-se a ausência de exportações a partir deste arranjo: nenhuma empresa atua no mercado internacional.

\subsection{INOVAÇÃO NO APL DE IMBITUVA}

A pesquisa incluiu uma série de questões relacionadas à inovação, que constitui o principal foco desta investigação. Em primeiro lugar, procurou-se saber se a empresa foi criada como resultado direto de uma inovação, para comercializar, produzir ou explorar aquela inovação. Mais da metade dos empresários (58\%) respondeu afirmativamente, contudo as entrevistas detalhadas revelaram que as

Revista de Administração e Inovação, São Paulo, v. 9, n. 1, p.141-166, jan./mar. 2012. 
Redes de cooperação e inovação localizada: estudo de caso de um arranjo produtivo local

inovações a que se referem dizem respeito a novos modelos e estilos. De fato, praticamente todas as empresas entraram no mercado com produtos e métodos de produção semelhantes aos já existentes no local.

A seguir, os empresários foram questionados se a empresa introduziu inovações nos quatro anos anteriores à pesquisa (período 2003-2006), e quais foram os tipos de inovação. O procedimento seguiu os padrões internacionais para pesquisas sobre inovação, estabelecidos a partir das orientações do Manual de Oslo (OCDE, 1997). Os resultados agregados estão indicados na Tabela 9. Enquanto diversas empresas informaram mais de um tipo de inovação, ressalta-se que 18 empresas (42\% do total) não introduziram inovações de nenhum tipo nesse período.

Tabela 9 - Inovações no período 2003-2006.

\begin{tabular}{l|c|c}
\multicolumn{1}{c|}{ Tipo de inovação } & \multicolumn{2}{c}{ Empresas } \\
\cline { 2 - 3 } & $\mathbf{N}$ & \% \\
\hline Novo produto/serviço, ou aperfeiçoamento significativo & 7 & $16,3 \%$ \\
\hline Novo processo produtivo, tecnologia nova ou equipamento novo & 21 & $48,8 \%$ \\
\hline Nova forma de venda ou distribuição & 8 & $18,6 \%$ \\
\hline Novo mercado & 6 & $14,0 \%$ \\
\hline Nova estrutura ou forma de organização empresarial & 2 & $4,7 \%$ \\
\hline inovações & 18 & $41,9 \%$ \\
\hline
\end{tabular}

Fonte: Elaborado pelo autor.

Mais uma vez, os dados quantitativos devem ser analisados criticamente com base nas informações obtidas nas entrevistas. O tipo predominante de inovação, observado em praticamente metade das empresas, refere-se à introdução de um novo processo produtivo, inclusive a aquisição de nova tecnologia, máquina ou equipamento que altere significativamente a produção. Neste caso, a inovação mais comum nas malharias da cidade foi a aquisição de máquinas eletrônicas programáveis de origem italiana, que produzem peças semiacabadas em malha. Em alguns casos isolados, trata-se da introdução de máquinas especializadas para determinados aspectos da produção, ou da aplicação de novos fios e materiais. Em geral, a utilização dessas novas tecnologias possibilita um aumento da qualidade e da produtividade, e também da automação dos processos, aumentando a capacidade de produção simultaneamente com a redução da mão de obra necessária.

Em segundo lugar, aparecem três tipos de inovação com importância semelhante: novos produtos, novas formas de venda e distribuição, e novos mercados, abrangendo $14 \%$ a $19 \%$ das empresas. A ocorrência de inovações organizacionais foi observada em apenas duas empresas (4,7\% do total). A análise das informações qualitativas revela que se trata em geral de inovações pouco expressivas. Por exemplo, empresas informam a abertura de novos mercados, novas formas de representação de vendas, a introdução de tamanhos especiais, produtos para segmentos específicos do 
mercado, novos produtos para verão, modelos mais diversificados e o uso de fios mais leves. Uma empresa fez uma tentativa de vendas pela Internet, mas abandonou temporariamente o projeto. Outra iniciou um projeto de exportação, mas também abandonou a iniciativa, que não foi bem-sucedida.

O impacto dessas inovações é bastante limitado, como seria de se esperar. Apenas 11,6\% das empresas opinam que a introdução da inovação causou mudanças fundamentais na maneira de a empresa operar, gerando atividades, produtos ou processos completamente novos. Para 39,5\% delas, a inovação causou uma melhora sensível na empresa, mas sem modificar substancialmente sua maneira de operar, enquanto para o restante $(48,8 \%)$ não houve inovação, ou esta não gerou mudanças significativas.

Para as empresas que introduziram algum tipo de inovação, foi investigado o grau de novidade dessa mudança, segundo a percepção dos próprios empresários. Verificou-se que em dois terços dos casos (67,7\% das empresas que inovaram) esta é nova somente para a própria organização; em 25,8\% dos casos, ela é considerada nova para o local, enquanto 6,5\% das empresas que introduziram inovações afirmam que isto representa uma novidade para todo o setor no Brasil.

\subsection{REDES DE RELACIONAMENTO NO APL DE IMBITUVA}

O terceiro componente da pesquisa de campo consistiu na coleta dos dados para o mapeamento das redes de relacionamento entre os atores envolvidos no APL. Os dados tabulados foram inseridos nos softwares de análise de redes sociais Ucinet e Netdraw, para análise quantitativa e visualização dos principais parâmetros da rede (Borgatti, Everett, \& Freeman, 2002).

A análise global dos dados da rede permite verificar que esta apresenta uma alta densidade $(0,99)$, conforme indicado na Tabela 10. Vale ressaltar que densidade é relação dos elos existentes e os possíveis, sendo assim, pode-se obter a variação de 0 a 1 . A alta densidade apresentada é reforçada pela pequena distância média entre os atores $(1,04)$, sendo necessário apenas um intermediário para que ocorra o contato entre uma organização e outra que não sejam ligadas por elos diretamente. Assim, para que uma organização estabeleça contato com outra organização da rede, com a qual ela nunca tenha se relacionado, é necessário em média apenas um intermediário. Com relação aos grupos da rede, verificou-se a existência de seis grupos. A distância média entre os grupos é pequena, sendo necessário localizar dois atores da rede, em média, para entrar em contato com qualquer um dos seis grupos.

Revista de Administração e Inovação, São Paulo, v. 9, n. 1, p.141-166, jan./mar. 2012. 
Tabela 10 - Características estruturais (globais) da Rede.

\begin{tabular}{l|c}
\hline \multicolumn{1}{c|}{ Característica } & Quantificação \\
\hline Densidade Geral & 0,99 \\
\hline Distância Média Geral da Rede & 1,04 \\
\hline Número de Grupos da Rede & 6 \\
\hline Distância Média entre os Grupos da Rede & 2 \\
\hline
\end{tabular}

Fonte: Elaborado pelo autor.

\subsection{ANÁLISE DAS INTERAÇÕES ENTRE OS ATORES DA REDE}

O primeiro aspecto a ser investigado foi a frequência dos contatos entre os atores da rede. Foram estabelecidos cinco níveis de frequência de contato com outras empresas ou instituições, a partir das indicações de cada empresário entrevistado, e estes foram enumerados com valores decrescentes. Como indicador da intensidade das interações, adotou-se a seguinte pontuação, somando-se o total de contatos realizados com outros atores: 4 pontos para contatos realizados uma vez ou mais por semana; 3 pontos para uma vez ou mais por mês; 2 pontos para uma vez ou mais por semestre; e 1 ponto para uma vez por ano ou menos. Com base nas indicações feitas pelos próprios empresários, verificou-se uma pontuação máxima de 166 e mínima de 4, representando as empresas que somam a maior e a menor intensidade de contatos respectivamente.

Os dados sobre interações entre os atores foram cruzados com outras informações obtidas na pesquisa, para verificar a existência de relações entre a frequência de contatos e outras variáveis, como inovação, desempenho dos negócios e idade das empresas. A análise foi necessariamente limitada pela quantidade de dados em relação ao número de variáveis. Embora a pesquisa seja caracterizada como um censo, já que todas as 43 empresas do APL foram pesquisadas, o número reduzido de observações permitiu apenas o cálculo de correlações entre as variáveis, além de estatísticas descritivas básicas. A Tabela 11 apresenta um resumo das comparações entre o nível médio de interação e as principais variáveis, indicando a pontuação média obtida pela ponderação da quantidade e frequência de contatos com outras empresas e instituições do APL.

Tabela 11 - Relações entre características da empresa e intensidade de interações.

\begin{tabular}{|c|c|c|c|}
\hline \multirow[b]{2}{*}{ Variável } & \multirow[b]{2}{*}{ Característica da empresa } & \multicolumn{2}{|r|}{ Empresas } \\
\hline & & $\mathbf{N}$ & $\begin{array}{l}\text { Pontuação média da } \\
\text { intensidade de contatos }\end{array}$ \\
\hline \multirow{2}{*}{ Inovação } & Introduziu inovação & 27 & 75,4 \\
\hline & Sem inovações & 16 & 72,3 \\
\hline \multirow{2}{*}{ Mudanças } & Inovação causou mudanças significativas & 22 & 88,5 \\
\hline & Sem mudanças associadas à inovação & 21 & 83,3 \\
\hline \multirow{2}{*}{ Desempenho } & Houve estabilidade ou expansão da produção & 25 & 91,1 \\
\hline & Houve redução da produção & 18 & 77,8 \\
\hline \multirow{3}{*}{ Idade } & Empresa criada há mais de 10 anos & 17 & 97,7 \\
\hline & Empresa com idade entre 8 e 10 anos & 14 & 77,2 \\
\hline & Empresa com menos de 8 anos & 12 & 79,8 \\
\hline
\end{tabular}

Fonte: Elaborado pelo autor.

Revista de Administração e Inovação, São Paulo, v. 9, n. 1, p.141-166, jan./mar. 2012. 
No cruzamento da intensidade de contatos com a variável inovação, verificou-se que as 27 empresas que relataram a introdução de inovações no período pesquisado apresentaram uma tendência pouco maior de interagir com outros atores do APL do que aquelas que não inovaram. A pontuação média dessas empresas foi de 75,4, enquanto as 16 empresas que não introduziram inovações apresentaram uma média de 72,3 pontos, ou seja, uma propensão a interagir com os demais atores em nível pouco inferior à das empresas inovadoras. $\mathrm{O}$ cálculo da correlação entre essas variáveis a partir dos dados brutos confirma que não existe diferença significativa entre os dois grupos, com um coeficiente $r=0,09$.

A relação entre o impacto das inovações e intensidade de contatos apresenta resultados semelhantes, também com um baixo coeficiente de correlação. Para as 22 empresas que opinam que a introdução da inovação causou mudanças fundamentais ou melhora sensível na empresa, a pontuação média é de 88,5. Para as empresas que não inovaram ou não tiveram mudanças significativas como resultado de inovações, a pontuação média é de 83,3.

A relação entre intensidade de interações e desempenho dos negócios é mais pronunciada, com base nos relatos dos empresários quanto à tendência dos últimos quatro anos. Para as 25 empresas (cerca de $55 \%$ do total) que relataram que houve estabilidade ou expansão da produção no período estudado, a pontuação média de frequência dos contatos é de 91,1. Para as demais, a pontuação média foi de 77,8. Da mesma forma, os 23 empresários que descrevem o estágio atual da sua empresa em termos gerais como estabilidade ou em expansão apresentam uma pontuação média de 95,5, contra uma média de 75,0 para os demais. Ou seja, pode-se inferir que as empresas com melhor desempenho tendem a interagir mais com os outros agentes do APL.

Comparando-se a intensidade de interações e idade das empresas, verificou-se que as 17 empresas mais antigas, criadas há mais de 10 anos, apresentam uma pontuação média de 97,5, revelando uma alta frequência de contatos. As 14 empresas com idade entre 8 e 10 anos interagem significativamente menos com outros atores, com a média de 77,2. O terceiro grupo, com 12 empresas criadas há menos de 10 anos, apresenta uma tendência um pouco maior a interagir com outras empresas e instituições, apresentando uma pontuação média de 79,8. Em relação a estas duas últimas variáveis (idade das empresas e desempenho dos negócios), embora os valores médios indiquem uma correlação maior com a intensidade de interações, cabe destacar que os coeficientes de correlação também são bastante baixos $(0,39$ e 0,47 respectivamente) . 


\subsection{TIPOS DE INTERAÇÕES}

A pesquisa abordou os principais tipos de interações entre os empresários, e também entre as empresas e as instituições que atuam no APL. Foi solicitado que os empresários indicassem quais pessoas, empresas ou entidades contribuíram para oito aspectos distintos: exemplo inicial, apoio ao desenvolvimento do negócio, capacitação técnica ou gerencial, inovação, provisão de recursos financeiros, treinamento do pessoal, acesso a mercados e atividades de cooperação. A análise de densidade por tipo de interação indicou que o principal motivo do estabelecimento de elos relacionais entre os atores são as relações de apoio $(0,060)$, seguidas pela cooperação $(0,026)$. Os baixos índices de densidade apresentados pela análise individual contrastam com a alta densidade global da rede $(0,99)$. Apresentam-se a seguir breves comentários sobre a análise que foi realizada para cada tipo de interação.

1. Exemplo: Com relação às pessoas ou entidades que contribuíram com ideias ou o conceito inicial para a empresa, observou-se que algumas empresas forneceram o exemplo para diversas outras, notadamente seis firmas, que estão entre as mais antigas da cidade. Com exceção de uma delas, que tem 11 anos de idade, as demais empresas que serviram de exemplo foram fundadas há mais de 20 anos.

2. Apoio: Para esta análise, solicitou-se aos empresários que indicassem quais pessoas ou instituições forneceram apoio ao desenvolvimento do negócio, na forma de conselhos, troca de ideias, apoio formal ou estímulo informal. A rede de apoio é a mais densa entre os tipos de interações existentes no APL de Imbituva, mas a sua densidade de 0,060 ainda pode ser caracterizada como baixa. Observou-se uma grande quantidade de relações recíprocas entre empresas. Destaca-se novamente que as empresas com maior envolvimento nas relações de apoio tendem a ser mais antigas. Com exceção de uma empresa, que foi fundada há 10 anos, as outras empresas com alto grau de centralidade possuem idades entre 16 e 25 anos. Observou-se ainda que as entidades que atuam no APL apresentam um papel limitado quanto a este aspecto; apenas cinco destas receberam indicações dos empresários como fontes dos tipos de apoio citados acima.

3. Capacitação: Os vínculos relacionados à capacitação incluem contatos para prestação de assistência formal, capacitação técnica ou gerencial. As principais fontes são o Sebrae e o IEL. Observou-se que muitas empresas não indicaram nenhum vínculo relacionado à capacitação, enquanto outras recorreram a mais de uma instituição e até a outras empresas do APL.

4. Inovação: Estes vínculos se referem a outras empresas ou entidades que forneceram ideias para inovação em produtos ou processos. As interações relacionadas à inovação ocorrem tanto com outras empresas como com instituições que atuam no local. Novamente, observou-se que poucas

Revista de Administração e Inovação, São Paulo, v. 9, n. 1, p.141-166, jan./mar. 2012. 
empresas indicaram esse tipo de vínculo. As interações oriundas das ações relacionadas à inovação podem ser observadas no sociograma da Figura 1, que apresenta os atores 15, 24 e 26 como principais atores de centralidade da rede.

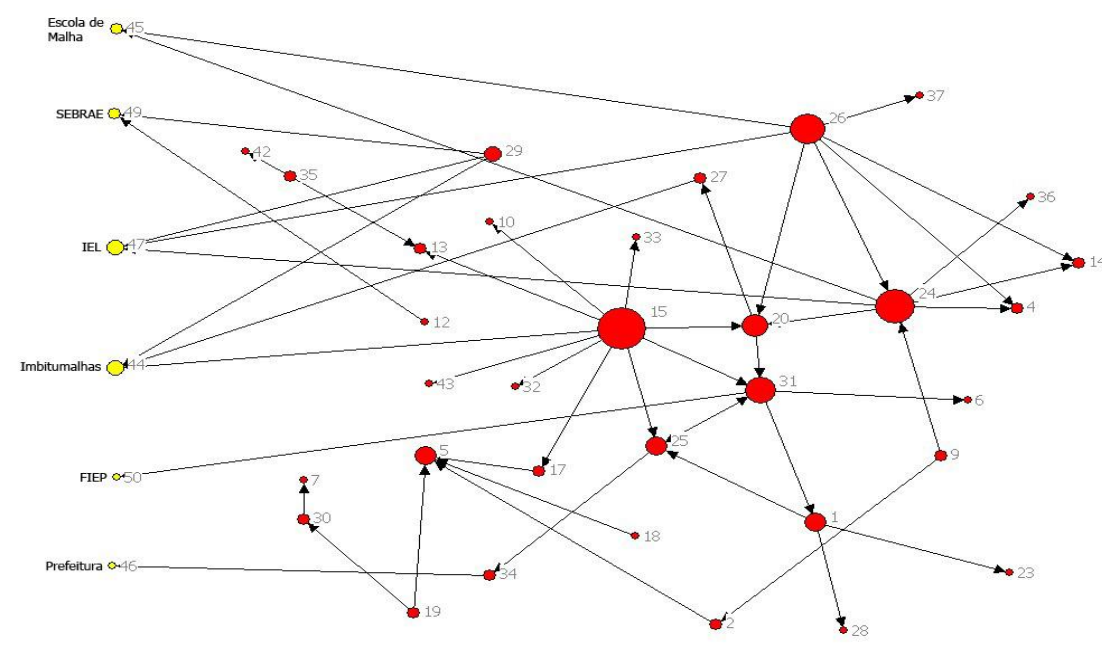

Figura 1 - Rede de vínculos relacionados ao aspecto "Inovação". Fonte: Elaborado pelo autor.

5. Recursos: Este tipo de interação refere-se exclusivamente à provisão de recursos financeiros. Um número relativamente pequeno de empresas recorreu a fontes externas de recursos, e o Banco do Brasil destaca-se como a principal fonte.

6. Treinamento: Este item refere-se a atividades voltadas à formação do pessoal ocupado nas malharias. Algumas entidades locais e estaduais assumem um papel importante neste aspecto, principalmente o IEL e o Sebrae. Várias empresas indicaram também outras empresas como fontes de treinamento.

7. Mercado: Este tipo de interação refere-se ao apoio obtido no acesso a mercados ou canais de distribuição. A análise da rede revelou que única instituição com papel relativamente importante neste aspecto é a Imbitumalhas. Por outro lado, a pesquisa indicou um número bastante alto de vínculos entre empresas com relação ao apoio no desenvolvimento de mercados.

8. Cooperação: Este tipo de interação é indicativo das relações de confiança e cooperação que se desenvolvem entre as empresas, compreendendo vínculos relacionados ao compartilhamento de equipamento ou instalações, por exemplo. A pesquisa revelou a existência de um núcleo de empresas que cooperam de forma bastante intensa, com diversos vínculos recíprocos (indicados pelas linhas mais grossas no sociograma da Figura 2). Os tamanhos dos nós são proporcionais ao número de vínculos que a empresa possui. As empresas que apresentam o maior número de vínculos de 
cooperação (identificadas pelos códigos 5, 20, 14, 31 e 16) estão entre as mais antigas do APL, e foram fundadas entre 21 e 30 anos atrás.

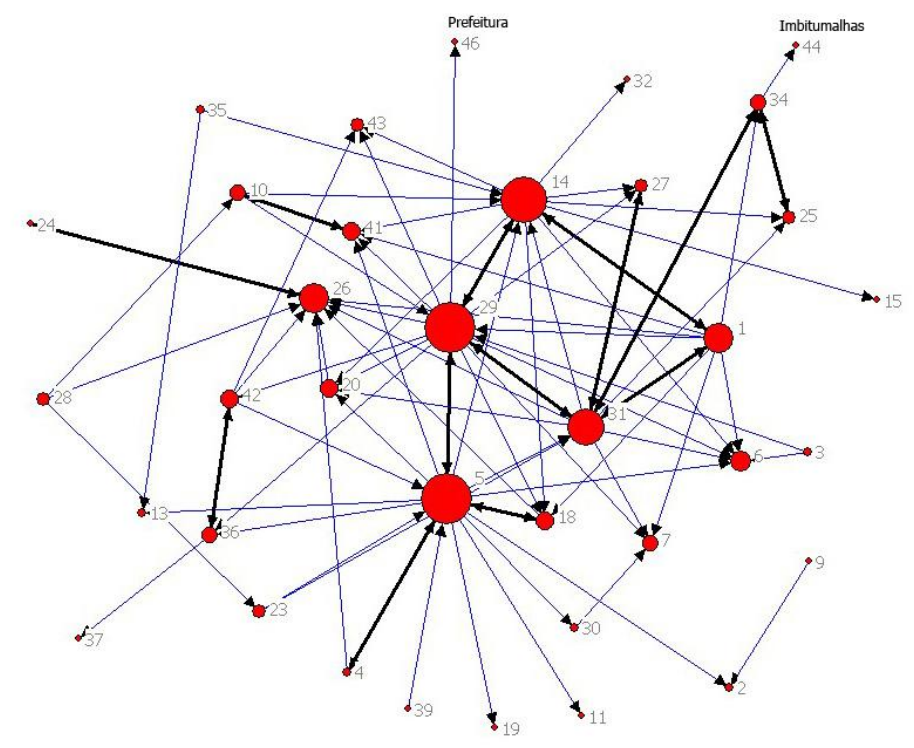

Figura 2 - Rede de vínculos relacionados ao aspecto "Cooperação". Fonte: Elaborado pelo autor.

\subsection{NÍVEL DE INTENSIDADE DE INTERAÇÕES COM AS INSTITUIÇÕES}

As interações entre as empresas e as instituições que atuam no APL foram analisadas separadamente, com base na pontuação média obtida pela ponderação da quantidade e frequência de contatos citados pelos empresários. A pontuação foi obtida a partir da soma dos contatos realizados com outros atores, atribuindo-se os seguintes pesos: 4 pontos para cada contato realizado uma vez ou mais por semana; 3 pontos para uma vez ou mais por mês; 2 pontos para uma vez ou mais por semestre; 1 ponto para uma vez por ano ou menos, e 0 quando nunca teve contato. Verificou-se que as empresas interagem mais intensamente com a Imbitumalhas (total de 104 pontos), que é uma entidade local constituída pelos próprios empresários. A seguir, aparece o Banco do Brasil (75 pontos), onde os contatos frequentes referem-se à necessidade de interações relacionadas aos negócios realizados com o banco. Outras instituições que aparecem com um nível relativamente alto de interações com os empresários (variando entre 48 e 55 pontos) são Federação das Indústrias do Estado do Paraná (FIEP), IEL, Sebrae e Prefeitura. Destaca-se ainda a quantidade significativa de empresários que afirmam que nunca tiveram contato com as diversas entidades ligadas ao desenvolvimento do APL.

Conforme indicado na Seção 4.8, cabe assinalar que a pesquisa incluiu uma análise detalhada dos tipos de interações entre as empresas e as instituições que atuam no APL. Observou-se que a maior variedade de atuação e quantidade de contatos envolveu três entidades: Sebrae, IEL e Imbitumalhas. Verificou-se que a maior quantidade de citações por tipo de apoio refere-se à capacitação e ao treinamento, refletindo o foco preponderante da atuação das entidades na percepção dos empresários. Revista de Administração e Inovação, São Paulo, v. 9, n. 1, p.141-166, jan./mar. 2012. 
Com relação à provisão de recursos financeiros, percebeu-se a importância do Banco do Brasil no suporte às empresas do APL de Imbituva.

\subsection{OBSTÁCULOS E FACILITADORES DO DESENVOLVIMENTO DAS EMPRESAS DO APL}

Nas entrevistas, os empresários informaram quais são os principais fatores facilitadores do desenvolvimento da empresa no APL de Imbituva. As respostas quanto ao grau de importância foram dadas em uma escala de 0 a 5, variando de sem importância a extremamente importante. A Tabela 12 mostra a somatória dos percentuais correspondentes aos graus de importância de 4 e 5 . Destaca-se a importância dada à imagem do Polo de Malharias de Imbituva como fator facilitador do desenvolvimento da empresa, seguida de aspectos relacionados à inovação em produtos, e da importância da interação com outros empresários.

Tabela 12 - Fatores que facilitaram o desenvolvimento da empresa no APL

\begin{tabular}{l|c}
\multicolumn{1}{c|}{ Fatores } & Importância \\
\hline Imagem do local como polo especializado & $83,7 \%$ \\
\hline Produto inovador & $79,1 \%$ \\
\hline Ajuda dos clientes na definição e teste de inovações & $76,8 \%$ \\
\hline Troca de ideias e cooperação com outros empresários & $74,5 \%$ \\
\hline Capacidade técnica/gerencial própria & $69,8 \%$ \\
\hline Existência de mão de obra qualificada no local & $53,5 \%$ \\
\hline Apoio de entidades estaduais ou federais & $48,9 \%$ \\
\hline A experiência trazida por funcionários para a empresa & $44,2 \%$ \\
\hline Apoio da prefeitura & $44,2 \%$ \\
\hline
\end{tabular}

Fonte: Elaborado pelo autor.

Similarmente, os empresários opinaram sobre os principais obstáculos ao desenvolvimento da empresa no APL de Imbituva. As respostas quanto ao grau de importância também foram dadas em uma escala de 0 a 5, variando de sem importância a extremamente importante". A Tabela 13 mostra os principais obstáculos, na opinião dos empresários. 
Tabela 15 - Principais obstáculos ao desenvolvimento da empresa no APL.

\begin{tabular}{l|c}
\multicolumn{1}{c|}{ Fatores } & Importância \\
\hline Concorrência externa de produtos similares & $83,7 \%$ \\
\hline Dificuldade de acesso a mercados & $67,4 \%$ \\
\hline Custo de mão de obra/encargos & $53,5 \%$ \\
\hline Custo dos insumos & $48,8 \%$ \\
\hline Falta de pessoal capacitado no local & $46,5 \%$ \\
\hline Dificuldade de acesso a recursos financeiros & $44,2 \%$ \\
\hline Dificuldade de acesso a recursos tecnológicos & $34,9 \%$ \\
\hline Outros & $23,3 \%$ \\
\hline Concorrência local de produtos similares & $2,3 \%$ \\
\hline
\end{tabular}

Fonte: Elaborado pelo autor.

A concorrência externa, mais especificamente dos produtos chineses, aparece com destaque como o obstáculo mais importante na visão dos empresários, seguida da dificuldade de acesso a mercados e aspectos relacionados aos custos. É interessante observar a pequena importância dada à concorrência local de produtos similares. Destaca-se ainda a preocupação com outros fatores - na maioria dos casos, os empresários referiam-se às temperaturas amenas dos últimos invernos, que dificultaram as vendas.

\section{CONSIDERAÇÕES FINAIS}

Diversas características do APL de malharias de Imbituva indicam que este ainda se encontra pouco consolidado, principalmente quanto à sua capacidade de promover o aprendizado coletivo e cumulativo, que é essencial para adquirir sustentabilidade e gerar respostas inovadoras em ambientes de incerteza (Camagni, 1995). Embora exista um equilíbrio entre maturidade e renovação das empresas, com uma idade média de 11,4 anos, a maioria foi criada para complementar a renda familiar ou proporcionar sustento básico, com perspectivas modestas de crescimento, baixos níveis de inovação e alcance geográfico bastante limitado.

A pesquisa de campo revelou que $42 \%$ das empresas não introduziram inovações nos últimos quatro anos, e que o tipo predominante de inovação refere-se à aquisição de novas máquinas. A análise das informações qualitativas revelou que as inovações em geral foram pouco expressivas, e que o seu impacto nas organizações foi bastante limitado. Em quase metade das empresas $(48,8 \%)$, ou não existiu atividade inovativa, ou esta não gerou mudanças significativas.

De um modo geral, as interações entre as empresas do APL são bastante frequentes, porém as interações com as instituições que atuam no local são bem menos intensas do que seria desejável para promover o intercâmbio de ideias e tecnologia. As empresas interagem mais intensamente com a sua associação local, a Imbitumalhas, e em menor grau com outras entidades, como Fiep, IEL, Sebrae e 
Prefeitura. Surpreendentemente, muitos empresários não relataram nenhum contato com as diversas entidades ligadas ao desenvolvimento do APL.

Verificou-se que as empresas que relataram a introdução de inovações apresentaram uma tendência pouco maior de interagir com outros atores do APL do que aquelas que não inovaram, enquanto a correlação entre intensidade de interações e desempenho dos negócios é mais pronunciada. Observou-se ainda que as empresas mais antigas interagem mais com outras empresas e instituições do APL. Porém, os coeficientes de correlação entre o grau de interação e as variáveis estudadas são baixos em todos os casos.

Com relação aos tipos de interações, observou-se que as empresas mais antigas exercem um papel importante como exemplo para novos empreendimentos, contribuindo com ideias ou o conceito inicial para diversas outras. Destaca-se também que a rede de apoio entre empresas para o desenvolvimento do negócio, na forma de conselhos, troca de ideias, apoio formal ou estímulo informal, é a mais densa $(0,060)$ no APL de Imbituva, envolvendo notadamente as empresas mais antigas. Por outro lado, a rede de vínculos relacionados à inovação em produtos ou processos apresenta densidade muito baixa $(0,014)$, tanto entre empresas como com as instituições que atuam no local.

Os vínculos relacionados à capacitação técnica ou gerencial indicam um papel importante do Sebrae e do IEL na rede local, enquanto o Banco do Brasil ocupa um papel central nos vínculos relacionados à provisão de recursos financeiros. As entidades locais e estaduais, principalmente IEL e Sebrae, também exercem um papel importante em atividades relacionadas ao treinamento do pessoal. A rede de vínculos relacionados ao apoio no acesso a mercados ou canais de distribuição revela que as instituições têm um papel pouco significativo nesse aspecto.

Finalmente, a rede de cooperação revela novamente o papel central das empresas mais antigas, mas apresenta densidade baixa (0,026), que sugere a falta de maturidade e aprofundamento dos vínculos interorganizacionais do APL. Este tipo de interação é extremamente importante, pois indica as relações de confiança e cooperação que se desenvolvem entre as empresas, compreendendo vínculos relacionados à especialização produtiva e ao compartilhamento de recursos produtivos. No APL de Imbituva, um núcleo reduzido de empresas coopera de forma bastante intensa, destacando-se o envolvimento das malharias mais antigas do APL.

Com relação à percepção dos empresários sobre os principais fatores facilitadores do desenvolvimento da empresa no APL, salienta-se a importância dada à imagem do local como Polo de Malharias, além de aspectos relacionados à inovação em produtos e às interações locais. No entanto, a análise de redes evidencia que os dois últimos aspectos ainda se encontram pouco desenvolvidos, sugerindo a importância de iniciativas que estimulem a inovatividade e a intensificação do aprendizado pela interação.

Revista de Administração e Inovação, São Paulo, v. 9, n. 1, p.141-166, jan./mar. 2012. 
Esta conclusão é reforçada pelas percepções dos obstáculos mais importantes na visão dos empresários. A preocupação com a concorrência externa e com a dificuldade de acesso a mercados também reflete a necessidade de estratégias que promovam a diversificação de produtos e mercados para assegurar o desenvolvimento sustentado do APL de malharias de Imbituva.

Essas observações revelam a necessidade de intervenções que unam os empresários e demais entidades que atuam no local para promover a inovação, a absorção de novos conceitos e tecnologias, e o desenvolvimento de mercados. As instituições governamentais devem ser indutoras e facilitadoras das ações coletivas localizadas, com amplo envolvimento dos diversos atores para garantir sinergia entre cooperação privada e apoio público no APL. O estímulo à formação e consolidação das redes de cooperação entre empresas deve aperfeiçoar a eficiência das suas interações, facilitar o aprendizado mútuo e reforçar as relações de confiança que são construídas ao longo do tempo no sistema produtivo local. A criação desse contexto capacitante para a inovação aumenta as perspectivas de sobrevivência do cluster num contexto de rápidas mudanças tecnológicas e organizacionais.

\section{REFERÊNCIAS}

Altenburg, T., \& Meyer-Stamer, J. (1999). How to promote clusters: policy experiences from Latin America. World Development, 27(9), 1693-1713.

Aral, S., \& Van Alstyne, M. (2008). Networks, information \& social capital (Working Paper, 468508). Cambridge, MA: MIT Sloan School of Management.

Baptista, R., \& Swann, P. (1998). Do firms in clusters innovate more? Research Policy, 27(5), 525540.

Barney, J. (1991) Firm resources and sustained competitive advantage. Journal of Management, 17(1), 99-120.

Bengtsson, M., \& Sölvell, Ö. (2004). Climate of competition, clusters and innovative performance. Scandinavian Journal of Management, 20(3), 225-244.

Berry, A. (1997). SME competitiveness: the power of networking and subcontracting. Washington, D.C.: Inter-American Development Bank.

Borgatti, S. P., Everett, M. G., \& Freeman, L. C. (2002). Ucinet for windows: software for social network analysis. Harvard, MA: Analytic Technologies.

Borgatti, S. P., \& Foster, P. (2003). The network paradigm in organizational research: a review and typology. Journal of Management, 29(6), 991-1013.

Camagni, R. (1995). Global network and local milieu: towards a theory of economic space. In S. Conti, E. Malecki \& P. Oinas (Eds.), The industrial enterprise and its environment: spatial perspectives (pp. 195-214). Aldershot: Avebury.

Revista de Administração e Inovação, São Paulo, v. 9, n. 1, p.141-166, jan./mar. 2012. 
Cândido, G., \& Abreu, A. (2000). Os conceitos de redes e as relações interorganizacionais: um estudo exploratório. Anais do Encontro da Associação Nacional de Pós-Graduação e Pesquisa em Administração, Florianópolis, RJ, Brasil, 24.

Cassiolato, J., \& Szapiro, M. (2003). Uma caracterização de arranjos produtivos locais de micro e pequenas empresas. In H. M. M. Lastres, J. E. Cassiolato, \& M. L. Maciel (Orgs.), Pequena empresa: cooperação e desenvolvimento local (pp. 35-50). Rio de Janeiro: Relume Dumará.

Crossan, M., \& Apaydin, M. (2010). A multi-dimensional framework of organizational innovation: a systematic review of the literature. Journal of Management Studies, 47(6), 1154-1191.

Federação das Indústrias do Estado de São Paulo. (2005). Pesquisa FIESP de inovação tecnológica. Recuperado em 10 de dezembro, 2011, de http://www.fiesp.com.br/tecnologia/pesquisas.aspx.

Freeman, C. (1995). The national system of innovation in historical perspective. Cambridge Journal of Economics, 19(1), 5-24.

Gorini, A. (2000). Panorama do setor têxtil no Brasil e no mundo: reestruturação e perspectivas. BNDES Setorial, 12, 17-50.

Hoffmann, R. C., \& Lins, H. N. (2002). Iniciativas e impasses em uma pequena aglomeração confeccionista: as malharias de Imbituva - Paraná, na ótica do debate sobre aglomerações industriais. In S. Cario, L. Pereira, \& M. Brollo (Org.), Economia paranaense: estudo de setores selecionados (pp. 213-249). Florianópolis: UFSC.

Instituto Brasileiro de Geografia e Estatística. (2003). Pesquisa industrial de inovação tecnológica PINTEC 2003. Recuperado em 24 de novembro, 2011, de http://www.ibge.gov.br/home/estatistica/economia/industria/pintec/2003.

Instituto Paranaense de Desenvolvimento Econômico e Social. (2006). Arranjo produtivo local de malhas do Município de Imbituva: estudo de caso: versão preliminar. Curitiba: Autor.

Love, J., \& Roper, S. (1999). The determinants of innovation: R\&D, technology transfer and networking effects. Review of Industrial Organization, 15(1), 43-64.

Lynch, P., Walsh, M., \& Harrington, D. (2010). Defining and dimensionalizing organizational innovativeness. Proceedings of the International CHRIE Conference-Refereed Track, San Juan, PR, USA.

Macpherson, A. (1997). A comparison of within-firm and external sources of product innovation. Growth and Change, 28(3), 289-308.

Olivares, J. E. L. (2002) Negociação para configurar o desenho da estrutura organizacional em rede. Caderno de Pesquisas em Administração, 9(3), 13-26.

Organisation for Economic Co-operation and Development. (1997). Oslo manual: guidelines for collecting and interpreting innovation data. Paris: Author.

Pittaway, L. A., Robertson, M., Munir, K., \& Denyer, D. (2004). Networking and innovation: $a$ systematic review of the evidence (Working Paper 2004/016). Lancaster: Institute for Entrepreneurship and Enterprise Development.

Porter, M. E. (1993). A vantagem competitiva das nações. Rio de Janeiro: Campus.

Porter, M. E. (1980). Competitive advantage. New York: The Free Press.

Revista de Administração e Inovação, São Paulo, v. 9, n. 1, p.141-166, jan./mar. 2012. 
Porter, M. E., \& Ketels, C. (2003). UK competitiveness: moving to the next stage (Management Research Forum; Summary Report 6). Boston: Institute of Strategy and Competitiveness.

Quandt, C. (2009). Inovação tecnológica. In R. Silva, Jr. (Org.), Empreendedorismo tecnológico (pp. 71-101). Curitiba: Instituto de Engenharia do Paraná.

Wasserman, S., \& Faust, K. (1999). Social network analysis: methods and applications (4 ${ }^{\text {th }}$ ed.). Cambridge: Cambridge University Press.

\title{
NETWORK OF COOPERATION AND INNOVATION: A STUDY CASE OF A LOCAL PRODUCTIVE ARRANGEMENT
}

\begin{abstract}
Collective strategies of cooperation among people and organizations constitute a major form of effective participation of social actors in the production of innovations and consequently, the competitiveness and economic growth of firms, regions and nations. The increasing importance of innovation clusters, alliances and inter-organizational networks highlights the relevance of this study, which seeks a better understanding of the process of local network creation and its contribution to innovation activities. The research approach emphasizes interactions and exchanges of knowledge and information among public and private agents in local networks. The empirical context for the analysis is a case study of the local production arrangement (APL), or cluster, of knitwear producers in Imbituva, Paraná, Brazil. The findings indicate that innovations in the APL have been inexpressive with a limited impact on the organizations. The study found a positive correlation between intensity of interactions, propensity to innovate and business performance. In addition, it was found that the older companies presented a more intense pattern of interactions. Network analysis reveals that innovation and local interaction aspects are poorly developed which suggests the importance of initiatives to foster innovativeness and learning by increasing interactions among companies and institutions in the APL.
\end{abstract}

Keywords: Cluster; Networks; Cooperation; Development; Innovation.

Data do recebimento do artigo: 05/05/2011

Data do aceite de publicação: 04/09/2011

Revista de Administração e Inovação, São Paulo, v. 9, n. 1, p.141-166, jan./mar. 2012. 